\title{
AUTOMATIC WATERING SYSTEM USING ARDUINO
}

P. Naveen

Master of Engineering (M.E). Assistant professor, Electronics and Communication Engineering, Kalasalingam Academy of Research and Education. Madurai, (India).

E-mail: naveenamp88@gmail.com ORCID: https://orcid.org/0000-0002-5202-2557

\begin{abstract}
R. Adapala
Student, Electronics and Communication Engineering, Kalasalingam Academy of Research and Education. Madurai, (India).

E-mail:rohanadapala07@gmail.com

ORCID: https://orcid.org/0000-0001-5212-2710
\end{abstract}

\begin{abstract}
A. Sreekanth
Student, Electronics and Communication Engineering, Kalasalingam Academy of Research and Education. Madurai, (India).

E-mail: sriikanth124@gmail.com

ORCID: https://orcid.org/0000-0001-7978-2671

B. Rakesh

Student, Electronics and Communication Engineering, Kalasalingam Academy of Research and Education. Madurai, (India).

E-mail: binnyrake@gmail.com

ORCID: https:// orcid.org/0000-0003-3532-9511
\end{abstract}

Recepción: 16/10/2019 Aceptación: 11/09/2020 Publicación: 30/11/2021

\section{Citación sugerida:}

Naveen, P., Adapala, R., Sreekanth, A., y Rakesh, B. (2021). Automatic watering system using Arduino. 3C Tecnología. Glosas de innovación aplicadas a la pyme, Edición Especial, (noviembre, 2021), 33-39. https:// doi.org/10.17993/3ctecno.2021.specialissue8.33-39 


\section{ABSTRACT}

The growing needs of man and the increasing population of earth causes the scarcity of water. This greatly affects the plants, and the requirement water management is high. Water use has been growing globally at more than twice the rate of population increases in the last century, and an increasing number of regions are reaching the limit at which water services can be sustainably delivered, especially in arid regions. In the present scenario the conventional methods of watering, like flood mode and sprinkler, is not that much effective and is responsible for water wastage. Improper watering systems create breeding areas for disease spreading organisms. Hence, the way watering pants must be smart, and this is achieved by watering plants depending on the necessity of plants and the moisture level of water. This project deals with an automated plant watering system that senses the moisture content of the soil thus determining the necessity of pumping water with the collected data. Also determines the minimum amount of water required to maintain the balance between the soil defensible water and environment parameters.

\section{KEYWORDS}

Arduino, Soil moisture sensor, Power supply, Relay. 


\section{INTRODUCTION}

At the present scenario, in the era of innovation where the technology is growing in terms of electrical and other new technologies, the life of people must be uncomplicated and more favorable and there is a need for lot of self-working system that are able to replace or bring down man's effort in their daily tasks. We propose a similar system called automatic self-plant watering system, which is basically a framework of monitoring planting and agriculture opportunities that uses sensors to detect the soil moisture content with a microcontroller and Arduino .Since asymmetrical watering results in plant efficient elements loss in the soil and may even results in spoil of the plants, Finding the method to find weather the watering is necessary or not and to give what we have to water the plants is foremost. Due to social process and inadequacy of place people started growing plants in an unfit windowsill location. It is very essential to use the water assets and a system is mandatory, to manage this task without man's existence. Machine-controlled watering system estimates and processes the existing plant and then materials required along with the amount of water quantity needed by that plant, dropping the amount of water to let the plants be water efficient.

\section{MATERIALS AND METHOD}

\section{Materials:}

Arduino, soil moisture sensor, power supply, relay, water motor.

\section{Method:}

The method of flowing water all by itself and monitoring the same in a display to let the user know about it is the second major task we need to solve. When the Arduino gets level 1 as input the user gets a display word of it and the first level of watering is done to maintain the water moisture level required to match the water. It has a system that can deliver a heavy load to pump the water. The opposite work happens when the logic-low is received.

We use a moisture detector that uses a sensing element in it to find the amount of moisture present in the soil and is connected to an external micro controller like an AVR or Arduino. The Arduino is connected to a computer to load a program to save the obtained results and 
give the output to a display and to control the amount of water flow. Also, we use a moisture sensor to find the amount of watering required for further flow of plant to be healthy.

\section{RESULTS}

The result of the project declares that, if the soil moisture is low then moisture sensor sends signal as level 1 to Arduino and it passes signal to relay which switches the power to the motor pump and provides water to the plant. If soil moisture is high, then the sensor send signal as level 0 and Arduino will not pass any signal to relay.

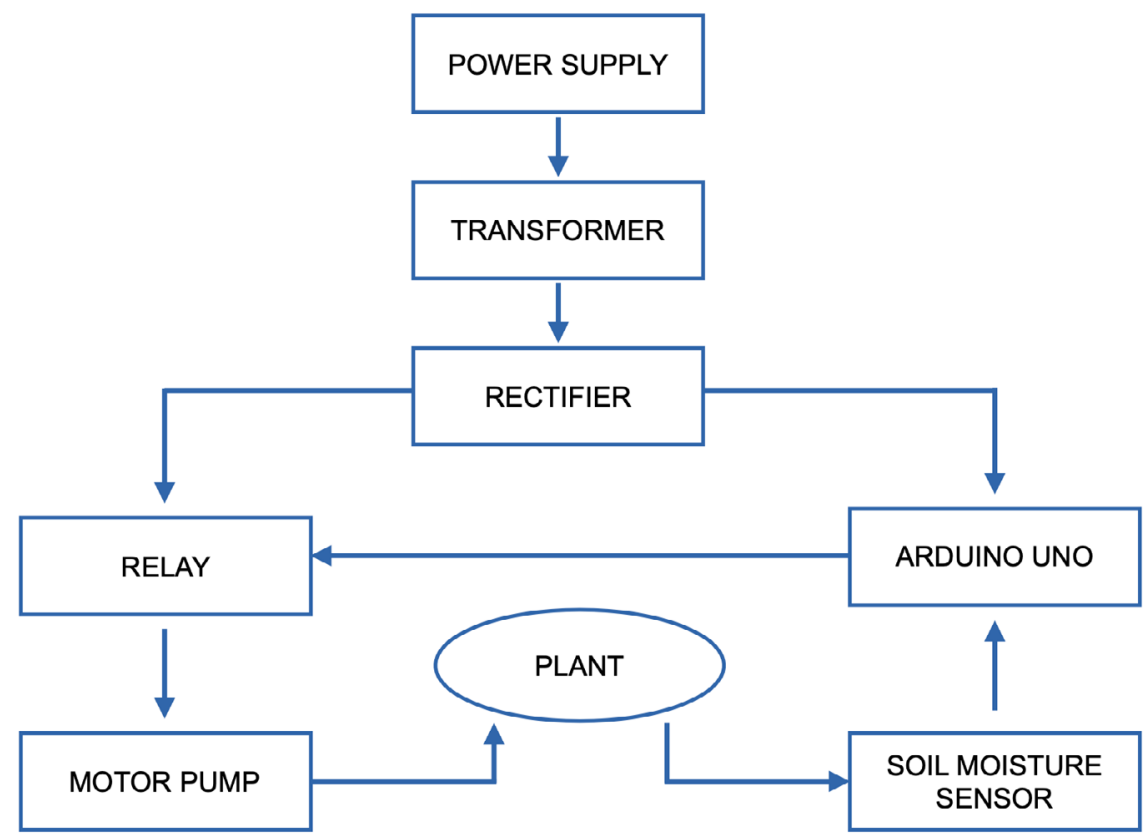

Figure 1. Block diagram.

Source: own elaboration.

\section{CONCLUSIONS}

The proposed system provides a vague output and cannot be dependent completely as all the plants are not having the same requirements for its watering needs. Some plants can be survived with less amount of water and withstand drought conditions. Monitoring a watering system based on the soil moisture level is not much efficient but provides a temporary solution to solve the problem. The development of the project must be further 
done depending on the amount of water required for the specific plant. Automatic irrigation systems improve water use and Reduce water wastage. This project can Contribute to socioeconomic development. It has a quick response and is computer user friendly. The primary use of this program is farmers and Gardeners do not have enough time for their watering, they do not miss crops or plants. This project is also an application for farmers wasting water unknowingly during irrigation. The main purpose of this smart project is, it is very innovative, user friendly, less time consuming, and more efficient than the existing system.

\section{REFERENCES}

Beckwith, R., Teibel, D., \& Bowen, P. (2004). Report from the Field: Results from an Agricultural Wireless Sensor Network. Proceedings of the 29th Annual IEEE International Conference on Local Computer Networks (LCN'O4). http:/ / profesores.elo.utfsm.cl/ agv/ research/interno06/papers/AgricultureWSN.pdf

Fu, Q., Xing, Z., \& Ma, Y. (2004). Applying Multivariate Auto Regression Model to Forecast the Water Requirement of Well Irrigation Rice in Sanjiang Plain. Nature and Science, 2(2), 8-14. http://www.sciencepub.net/nature/0202/02fu.pdf

Kim, Y., \& Evans, R. G. (2009). Software design for wireless sensor-based site-specific irrigation. Computers and Electronics in Agriculture, 66(2), 159-165. https://doi. org/10.1016/j.compag.2009.01.007

Kim, Y., Evans, R. G., \& Iversen, W. M. (2008). Remote Sensing and Control of an Irrigation System Using a Distributed Wireless Sensor Network. IEEE Transactions on Instrumentation and Measurement, 57(7), 1379-1387. https://doi.org/10.1109/ TIM.2008.917198

Li, F., Wang, B., Huang, Y., Teng, Y., \& Cai, T. (2011). Study on the Management System of Farmland Intelligent Irrigation. In Li, D., Liu, Y., \& Chen, Y. (eds.) Computer and Computing Technologies in Agriculture IV. CGTA 2010. IFIP Advances in Information and Communication Technology, vol. 345. Springer, Berlin, Heidelberg. https:/ / doi. org/10.1007/978-3-642-18336-2_83 
Morais, R., Valente, A., \& Serodio, G. (2005). A Wireless Sensor Network for Smart Irrigation and Environmental Monitoring: A Position Article. Data Acquisition Station for Agriculture. https://www.researchgate.net/publication/229000796_A_wireless_sensor_ network_for_smart_irrigation_and_environmental_monitoring_A_position_article

\section{Putjaikal, N., Phusae, S., Chen-im, A., Phunchongharn, P., \& Akkarajitsakul, K.} (2016). A Control System in an Intelligent Farming by using Arduino Technology. In Fifth ICT International Student Project Conference (ICT-ISPC). http://smartfasal.in/ wp/wp-content/uploads/2019/09/A-control-system-in-an-intelligent-farming-byusing-arduino-technology.pdf

Rehman, A.-U., \& Shaikh, Z. A. (2008). Towards Design of Context Aware Sensor Grid Framework for Agriculture. Proceedings of World Academy of Science, Engineering and Technology. https://www.researchgate.net/publication/236960807_Towards_ design_of_context-aware_sensor_grid_framework_for_agriculture

Wang, N., Zhang, N., \& Wang, M. (2006). Wireless sensors in agriculture and food industry - Recent development and future perspective. Computers and Electronics in Agriculture, 50(1), 1-14. https://doi.org/10.1016/j.compag.2005.09.003 
